Article

\title{
Optoelectronic Properties and Structural Characterization of GaN Thick Films on Different Substrates through Pulsed Laser Deposition
}

\author{
Wei-Kai Wang ${ }^{1, *}$, Shih-Yung Huang ${ }^{2}$, Ming-Chien Jiang ${ }^{3}$ and Dong-Sing Wuu ${ }^{3}$ \\ 1 Department of Materials Science and Engineering, Da-Yeh University, Changhua 51591, Taiwan \\ 2 Department of Industrial Engineering and Management, Da-Yeh University, Changhua 51591, Taiwan; \\ syh@mail.dyu.edu.tw \\ 3 Department of Materials Science and Engineering, National Chung Hsing University, \\ Taichung 40227, Taiwan; jiang.player@gmail.com (M.-C.J.); dsw@dragon.nchu.edu.tw (D.-S.W.) \\ * Correspondence: wk@mail.dyu.edu.tw; Tel.: +886-4-851-1888
}

Academic Editor: Jiwang Yan

Received: 1 December 2016; Accepted: 11 January 2017; Published: 17 January 2017

\begin{abstract}
Approximately 4- $\mu$ m-thick GaN epitaxial films were directly grown onto a GaN/sapphire template, sapphire, $\mathrm{Si}(111)$, and $\mathrm{Si}(100)$ substrates by high-temperature pulsed laser deposition (PLD). The influence of the substrate type on the crystalline quality, surface morphology, microstructure, and stress states was investigated by X-ray diffraction (XRD), photoluminescence (PL), atomic force microscopy (AFM), transmission electron microscopy (TEM), and Raman spectroscopy. Raman scattering spectral analysis showed a compressive film stress of $-0.468 \mathrm{GPa}$ for the GaN/sapphire template, whereas the $\mathrm{GaN}$ films on sapphire, $\mathrm{Si}(111)$, and $\mathrm{Si}(100)$ exhibited a tensile stress of 0.21 , 0.177 , and $0.081 \mathrm{GPa}$, respectively. Comparative analysis indicated the growth of very close to stress-free $\mathrm{GaN}$ on the $\mathrm{Si}(100)$ substrate due to the highly directional energetic precursor migration on the substrate's surface and the release of stress in the nucleation of $\mathrm{GaN}$ films during growth by the high-temperature $\left(1000^{\circ} \mathrm{C}\right)$ operation of PLD. Moreover, TEM images revealed that no significant $\mathrm{GaN}$ meltback (Ga-Si) etching process was found in the GaN/Si sample surface. These results indicate that PLD has great potential for developing stress-free GaN templates on different substrates and using them for further application in optoelectronic devices.
\end{abstract}

Keywords: GaN; pulsed laser deposition; transmission electron microscopy

\section{Introduction}

Gallium nitride $(\mathrm{GaN})$ and its related III-nitride materials are excellent wide direct band-gap $(3.4 \mathrm{eV})$ semiconductors due to their potential properties of high saturation velocity in an electric field, high breakdown electric field, and electron mobility—all of which are necessary for the development of next-generation devices and applications that are high frequency, highly efficient, and can effectively power switching devices [1-3]. However, due to the lack of suitable native or lattice-matched substrates, $\mathrm{GaN}$ epilyers are usually grown on sapphire, $\mathrm{SiC}$, and $\mathrm{Si}$ substrates. This presents a serious problem, as a high defect density and a large biaxial stress in the heteroepitaxy of the GaN epilayers are generated by mismatches in the lattice structure and thermal expansion coefficients between the epilayers and the Si substrate. These growth-induced defects (such as threading dislocations, stacking faults, voids, and point defects) limit the performance and reliability of GaN-based devices [4-6]. ZnO-related materials may be closely lattice-matched with $\mathrm{GaN}$, but the drawback of the $\mathrm{ZnO}$ single crystalline wafer is that it is still expensive [7]. Substrates that produce a low density of defects present the most effective possible approach for reducing defects in epitaxial films. The most widely used methods for growing 
GaN with low defect density are hydride vapor phase epitaxy (HVPE) and metalorganic chemical vapor deposition (MOCVD) [8,9]. GaN thin films with high-quality and low-density of defects can also be grown by ion-beam assisted MBE $[10,11]$. The reaction chamber in an HVPE system is often made of quartz, which is not operational under high temperature. An MOCVD system requires a high-temperature growth process, which consumes considerable electric power and thereby produces high running costs and the possibility of air pollution due to the toxicity of the metal-organic chemicals in the precursor gas. Pulsed laser deposition (PLD) is a promising technique that can address these problems [12-14]. PLD is interesting, as it allows for in situ processing of the multilayer structure via multiple targets, stoichiometric transfer deposition from the target to the substrate, flexible doping options for complex compositions, and a highly directionally distributed energetic precursor produced by the laser ablation of a target. Most discussions on PLD focus on studying the influence of growth conditions on the properties of GaN films [15-19]. Several previous studies have reported how PLD enables the growth of high-quality III-nitrides on other substrates [20-24]. Since the considerable scale and production cost of native GaN substrates would be too much, GaN templates on foreign substrates are good choices for the heteroepitaxial deposition of GaN-based devices. In this study, the crystalline quality, surface morphology, optoelectronic and structural properties related to GaN thick film grown on different substrates as a GaN templates through high-temperature PLD are characterized and compared.

\section{Experimental}

All GaN film samples were deposited on different substrates by PLD at $1000{ }^{\circ} \mathrm{C}$ in a nitrogen plasma ambient atmosphere. The chamber was pumped down to $10^{-6}$ Torr before the deposition process began, and $\mathrm{N}_{2}$ gas (with a purity of $99.999 \%$ ) was introduced. The working pressure once the $\mathrm{N}_{2}$ plasma was injected was $1.13 \times 10^{-4}$ Torr. A KrF excimer laser $(\lambda=248 \mathrm{~nm}$, Lambda Physik, Fort Lauderdale, FL, USA) was employed as the ablation source and operated with a repetition rate of $1 \mathrm{~Hz}$ and a pulse energy of $60 \mathrm{~mJ}$. The average growth rate of the GaN film was approximately $1 \mu \mathrm{m} / \mathrm{h}$. The laser beam was incident on a rotating target at an angle of $45^{\circ}$. The GaN target was fabricated by HVPE and set at a fixed distance of $9 \mathrm{~cm}$ from the substrate before being rotated at $30 \mathrm{rpm}$ during film deposition. In this case, $\sim 4 \mu$ m-thick $\mathrm{GaN}$ films were grown on a GaN/sapphire template (sample A), sapphire (sample B), Si(111) (sample C), and Si(100) (sample D). For the GaN on sample A, a 2- $\mu \mathrm{m}$ GaN layer was firstly deposited on sapphire substrate by MOCVD. Scanning electron microscopy (SEM, S-3000H, Hitachi, Tokyo, Japan), transmission electron microcopy (TEM, H-600, Hitachi, Tokyo, Japan), atomic force microscopy (AFM, DI-3100, Veeco, New York, NY, USA), double-crystal X-ray diffraction (XRD, X'Pert PRO MRD, PANalytical, Almelo, The Netherlands), low-temperature photoluminescence (PL, Flouromax-3, Horiba, Tokyo, Japan), and Raman spectroscopy (Jobin Yvon, Horiba, Tokyo, Japan) were employed to explore the microstructure and optical properties of the GaN templates deposited on different substrates. The electrical properties of the GaN films were determined by Van der Pauw-Hall measurement under liquid nitrogen cooling at $77 \mathrm{~K}$.

\section{Results and Discussion}

Figure 1 shows a low-temperature PL spectra (at $77 \mathrm{~K}$ ) of GaN films grown on different substrates. PL spectra of GaN grown on different substrates are dominated by the near-band-edge emission at around $360 \mathrm{~nm}$. The full width at half maximum (FWHM) of the GaN films produced on samples A $(4 \mathrm{~nm})$ and $B(8 \mathrm{~nm})$ are narrower than that of the films grown on samples $C(10 \mathrm{~nm})$ and D $(13 \mathrm{~nm})$, indicating the low defect density and high crystalline quality of the GaN films due to their lower lattice mismatch, which is consistent with the XRD results. Similar trends of the yellow band-emission peak on these samples were also observed (data not shown here). The yellow luminescence is related to deep level defects in GaN [25]. Figure 2 shows a comparison of the typical XRD patterns of GaN (0002) films grown on different substrates. It can be seen that there is a variation in the FWHM value of the (0002) diffraction peak, and intensities of the GaN diffraction peak on the different substrates were 
obtained at around 34.5 degrees. The intensity of $\mathrm{GaN}(0002)$ in sample A is the strongest among all samples, which indicates that the GaN films on the GaN/sapphire template are highly c-oriented and have better crystalline quality. The FWHM of GaN (0002) values for samples A, B, C, and D were measured at $0.19^{\circ}, 0.51^{\circ}, 0.79^{\circ}$, and $1.09^{\circ}$, respectively. However, the XRD peak intensity increases as FWHM decreases; this is attributed to the increase in the crystallite size due to either the aggregation of small grains or grain boundary movement during the growth process. Since the FWHM of the XRD diffraction peak is relative to the average crystallite grain size in the film [26], the grain size of GaN grown on the different substrates is calculated using the Debye-Scherer equation [27]:

$$
D=0.9 \lambda / F W H M \cos \theta
$$

where $D$ is the crystallite size, $\lambda$ is the $\mathrm{X}$-ray wavelength, and $\theta$ is the diffraction angle. The crystallite sizes of samples A, B, C, and D are estimated to be $57,20,13$, and $9 \mathrm{~nm}$, respectively. These results indicate that the crystalline quality of $\mathrm{GaN}$ films grown on samples $\mathrm{A}$ and $\mathrm{B}$ is better than that of the films grown on samples $C$ and $D$.

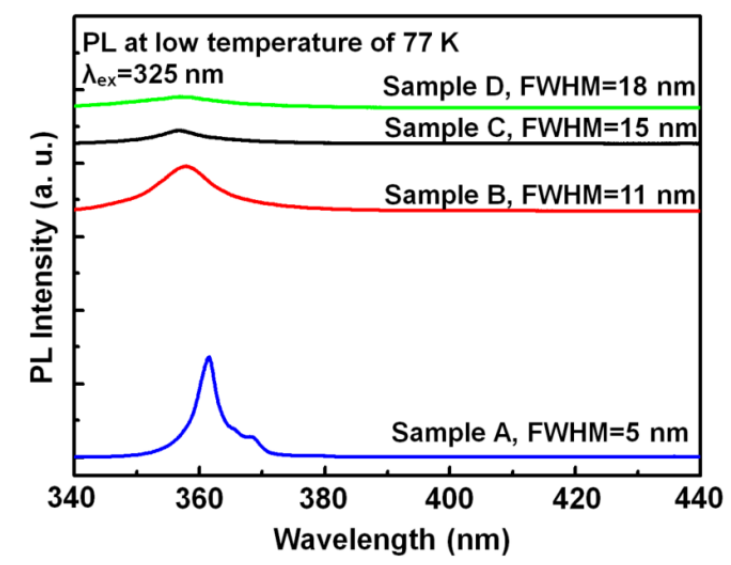

Figure 1. Low-temperature photoluminescence (PL) spectra (at $77 \mathrm{~K}$ ) of GaN films grown on different substrates. FWHM: full width at half maximum.

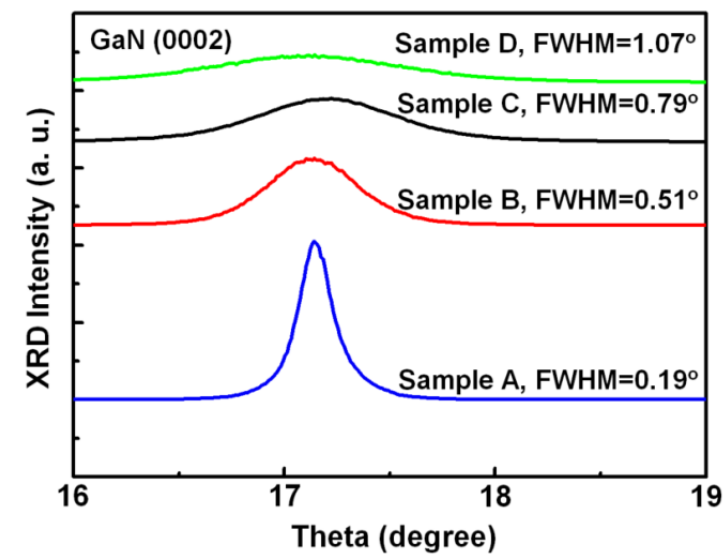

Figure 2. X-ray diffraction (XRD) measurements results of GaN films grown on different substrates.

Figure 3 shows plane-view SEM pictures of GaN films grown on various substrates. The surface morphologies show different features, as they are strongly dependent on the types of substrates used. The surface of GaN films in samples A and B was mirror-like, indicating less of a lattice mismatch between $\mathrm{GaN}$ and sapphire (Figure 3a,b). The smooth surface might be due to the high kinetic energy needed by PLD for GaN precursor migration and diffusion on the substrates' surface [28]. A rough GaN 
film surface, meanwhile, was observed in sample C (Figure 3c). Sample D presented an incomplete island coalescence process with a hexagonal structure, as shown in Figure $3 \mathrm{~d}$. This result indicates that GaN films on $\mathrm{Si}(100)$ have a hexagonal phase. The different $\mathrm{GaN}$ film structure of the grains can be attributed to the different lattice structure of the Si substrate [29]. The surface morphology and roughness of the GaN films grown on different substrates were carried out by AFM measurements with the scanning area of $10 \times 10 \mu \mathrm{m}^{2}$, as shown in Figure 4. In Figure 4, the root-mean-square RMS values for samples A, B, C, and D are 2.1, 3.4, 14.3, and $17.7 \mathrm{~nm}$, respectively. The film grown in samples A and B exhibited quite a smooth surface, with the RMS roughness being 3.4 and $2.1 \mathrm{~nm}$, respectively, and the RMS surface roughness of samples $C$ and D was estimated as 14.3 and $17.7 \mathrm{~nm}$, respectively. The large values for the surface roughness of the $\mathrm{GaN}$ films in samples $\mathrm{C}$ and $\mathrm{D}$ might be due to the large lattice mismatch between the film and the substrates. A decrease in surface roughness occurs with an increase in grain size, as mentioned in the XRD results.
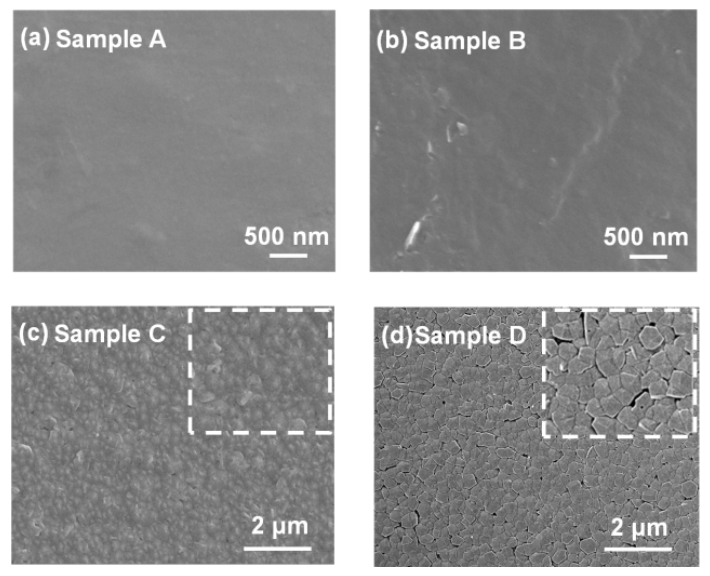

Figure 3. Scanning electron microscopy (SEM) surface image of GaN films grown on different substrates: (a) GaN/sapphire template (sample A); (b) sapphire (sample B); (c) Si(111) (sample C); (d) $\operatorname{Si}(100)$ (sample D).

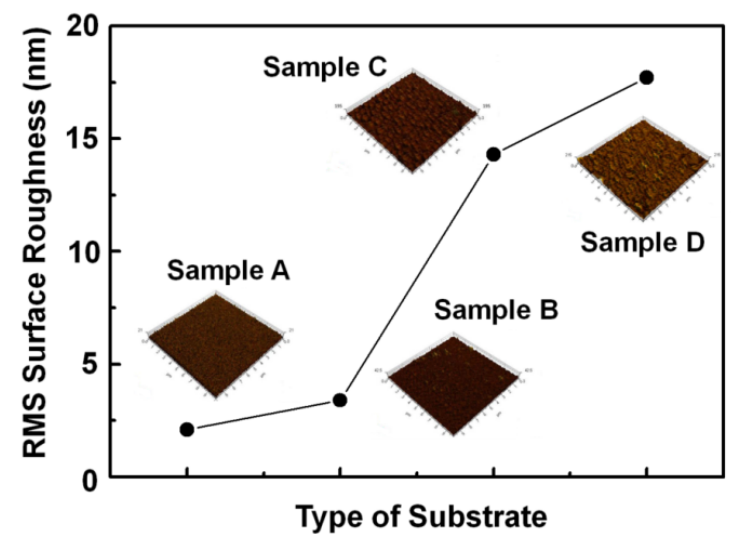

Figure 4. Atomic force microscopy (AFM) observations of GaN films grown on different substrates. RMS: root-mean-square.

The electrical resistivity of the GaN films grown on different substrates is shown in Figure 5a. The electrical resistivity of the four samples was found to be in the range $16.2-32.8 \Omega \cdot \mathrm{cm}$. The electrical resistivity of sample D was the largest, while that of sample A was the smallest. The electrical resistivity correlates with defect density, and the high defect density in the films may cause a decrease in the electrical resistivity [30]. The values of electrical resistivity of samples $C$ and $D$ were very close, which is consistent with the structural features of the films grown on these substrates, as discussed 
above. As electrical resistivity is inversely proportional to the carrier concentration and carrier mobility, the electrical resistivity of the films grown on the different substrates can be determined from their measurements. Low-temperature Hall measurement data from GaN films grown on the different substrates are shown in Figure 5b,c. Sample A showed the lowest carrier concentration and highest carrier mobility, thereby resulting in an increased number of conductive paths. The carrier concentration in sample D was higher than that in the others, whereas its carrier mobility was the lowest. This can be attributed to the existence of a high intrinsic defect and several grain boundaries in the film. These defects trap and scatter moving electrons, thus decreasing their mobility in the GaN films [31,32].

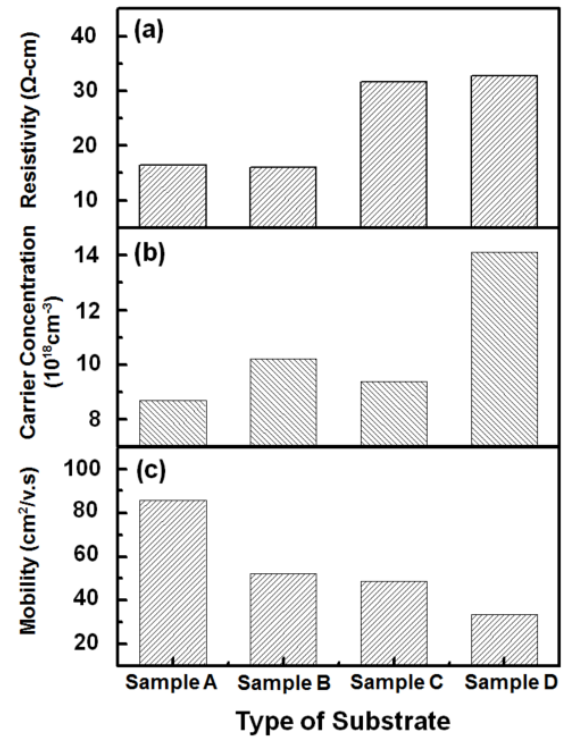

Figure 5. Variation in (a) resistivity; (b) carrier concentration; and (c) mobility of GaN films with different substrates.

To further clarify the stress behaviors among the four samples, Raman scattering spectroscopy was performed, and the results are shown in Figure 6. The $\mathrm{E}_{2}$-high phonon mode is very sensitive to biaxial strain, and is extensively used to characterize the in-plane stress state of the GaN epilayer [33].

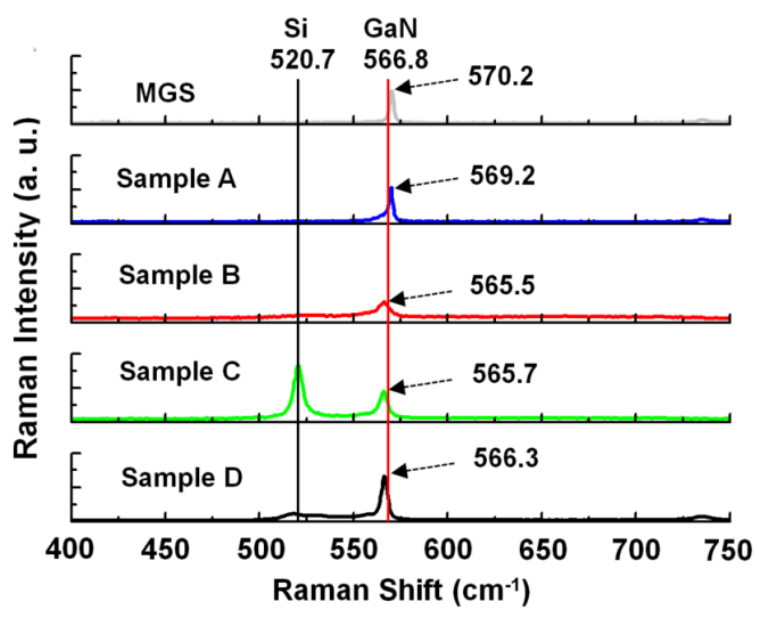

Figure 6. Raman spectra of GaN films for samples MGS (metalorganic chemical vapor deposition (MOCVD)-grown GaN on sapphire), A, B, C, and D. 
The relationship between biaxial stress and Raman shift can be shown by the formula:

$$
\sigma=\Delta \omega / k
$$

where $\sigma$ is the biaxial stress, $\Delta \omega$ is the Raman shift, and $k$ is the Raman stress coefficient of $6.2 \mathrm{~cm}^{-1} \cdot \mathrm{GPa}^{-1}$ for GaN [34]. Generally, a blue shift in an $\mathrm{E}_{2}$-high phonon peak indicates compressive stress, while a red shift indicates tensile stress [35]. It has been found that an $\mathrm{E}_{2}$-high peak position is substrate dependent, which implies that there are different stress states in those samples. In the present case, the GaN E2-high peaks of samples MGS (MOCVD-grown GaN on sapphire), A, B, C, and D were evaluated as $520.7,569.7,565.5,565.7$, and $566.3 \mathrm{~cm}^{-1}$, respectively. Compared to the intrinsic value of $566.8 \mathrm{~cm}^{-1}$ for the stress-free GaN, samples B, C, and D were under tensile stress, while sample A was under compressive stress [36]. This can be due to the rapid release of stress in the nucleation of GaN films during the initial growth by high-temperature $\left(1000^{\circ} \mathrm{C}\right) \mathrm{PLD}$. This observed result is also consistent with those reported by Wang et al. [37]. Sample D had minimum stress, likely caused by the growth of polygonal island structures and defects generated in the films, which is consistent with the SEM results [38]. There is a large difference in the lattice mismatch and thermal expansion between $\mathrm{GaN}$ and $\mathrm{Si}$ when compared to the GaN/sapphire template and sapphire. The calculated values of stress for GaN grown on different substrates are shown in Figure 7. The Raman spectra of the MGS sample is displayed for comparison, as shown in Figure 7. The GaN E 2 peak of MGS was evaluated at $570.2 \mathrm{~cm}^{-1}$ with a compressive stress value of $-0.548 \mathrm{GPa}$, which is larger than the compressive stress value of -0.468 for sample B. It can be concluded that the PLD growth method is beneficial for the release of stress in the films.

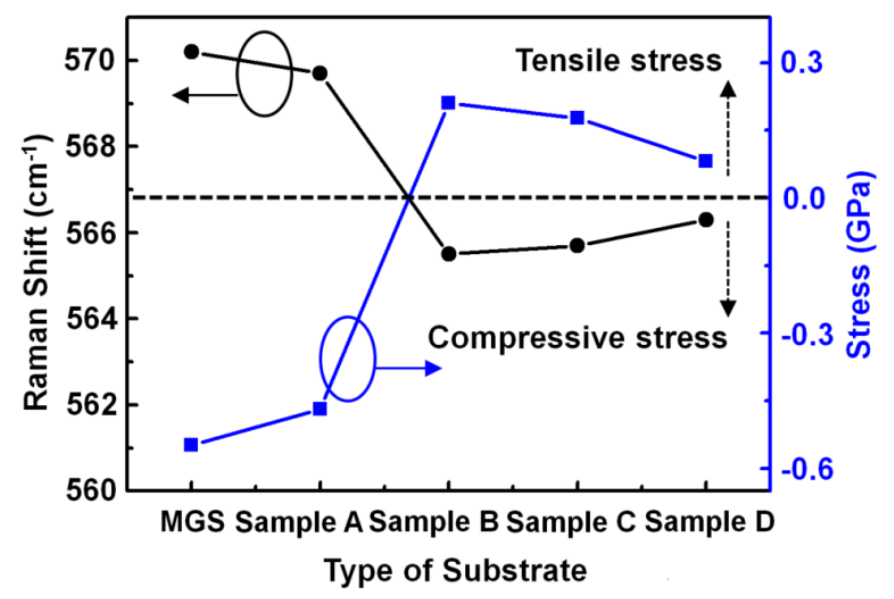

Figure 7. Residual stress and its corresponding $E_{2}$ Raman shift for samples MGS, A, B, C, and D.

Cross-sectional TEM images were used to investigate the GaN-on-Si meltback-etching reaction with PLD operating at a high temperature of $1000{ }^{\circ} \mathrm{C}$. Previously, it was reported that the meltback-etching process caused by alloying reaction Ga with Si leads to a rough GaN surface and deep hollows in the Si substrate [39,40]. Figure 8a,b shows the TEM images of the GaN films grown on $\mathrm{Si}(111)$ and $\mathrm{Si}(100)$, respectively. From Figure $8 \mathrm{a}, \mathrm{b}$, it can clearly be observed that no significant $\mathrm{Ga}-\mathrm{Si}$ meltback occurred at the GaN/Si surface; this is likely because of the suppressed interaction between the GaN epitaxy films and the Si substrates developed through PLD. 

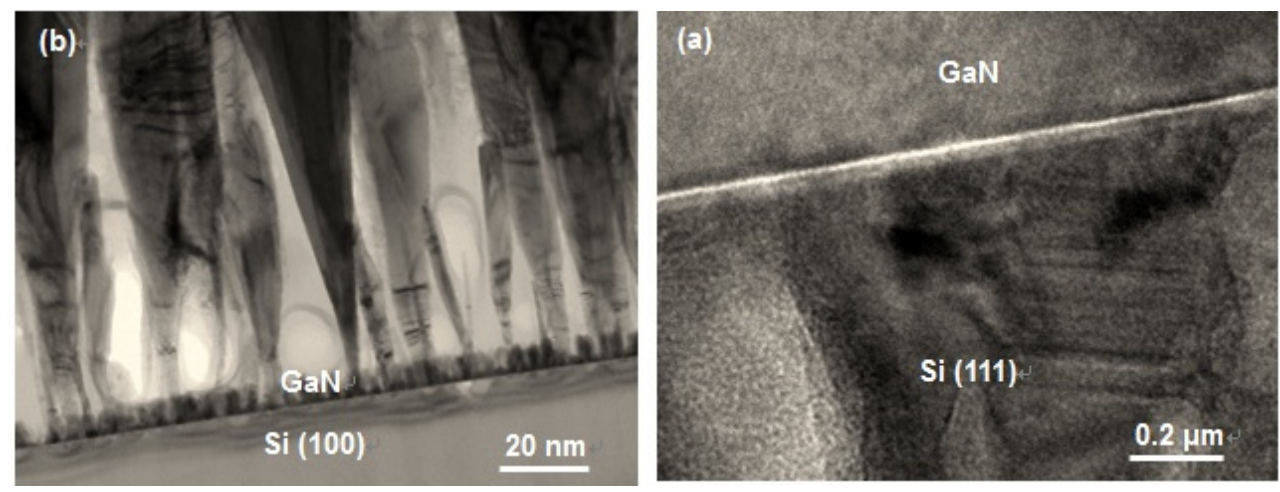

Figure 8. Cross-sectional TEM pictures of GaN films on samples (a) C and (b) D.

\section{Conclusions}

We investigated the GaN thick films grown on a GaN/sapphire template, sapphire, $\mathrm{Si}(111)$, and $\mathrm{Si}(100)$ by high-temperature PLD. The substrate effect on GaN crystalline growth quality, surface morphology, stress behavior, and interface property were studied. This paper demonstrates the potential of using high-temperature PLD as a growth method for preparing GaN templates that exhibit improved device performance.

Acknowledgments: This work was supported by Ministry of Science and Technology of Taiwan (grant No. 105-2632-E-212-001) and the authors wish to express their sincere gratitude for the financial and technical support from the advanced Industry Technology Centre of National Chung Hsing University, Taiwan.

Author Contributions: Wei-Kai Wang organized and designed the experimental procedures; Shih-Yung Huang and Ming-Chien Jiang contributed the films measurement results. Dong-Sing Wuu supported the experimental and measurement tools. All authors read and approved the final version of the manuscript to be submitted.

Conflicts of Interest: The authors declare no conflict of interest.

\section{References}

1. Tan, S.; Suzue, T.; Selvaraj, S.L.; Egawa, T. Influence of growth parameters and thickness of AlN spacer on electrical properties of AlGaN/AlN/GaN high-electron-mobility transistors grown on 4-inch Si substrate. Jpn. J. Appl. Phys. 2009, 48. [CrossRef]

2. Yeh, C.T.; Wang, W.K.; Shen, Y.S.; Horng, R.H. 1.48-kV enhancement-mode AlGaN/GaN high-electron-mobility transistors fabricated on 6-in. silicon by fluoride-based plasma treatment. Jpn. J. Appl. Phys. 2016, 55. [CrossRef]

3. Palacios, T.; Chakraborty, A.; Heikman, S.; Keller, S.; DenBaars, S.P.; Mishra, U.K. AlGaN/GaN high electron mobility transistors with InGaN back-barriers. IEEE Electron Device Lett. 2006, 27, 13-15. [CrossRef]

4. Chen, Z.M.; Zheng, Z.Y.; Chen, Y.D.; Wu, H.L.; Tong, C.S.; Wang, G.; Wu, Z.S.; Jiang, H. Threading edge dislocation arrays in epitaxial GaN: Formation, model and thermodynamics. J. Cryst. Growth 2014, 387, 48-51. [CrossRef]

5. Wuu, D.S.; Wang, W.K.; Wen, K.S.; Ling, S.C.; Huang, S.Y.; Lin, C.F.; Horng, R.H. Defect reduction and efficiency improvement of near-ultraviolet emitters via laterally overgrown $\mathrm{GaN}$ on a GaN/patterned sapphire template. Appl. Phys. Lett. 2006, 89, 161105. [CrossRef]

6. Cao, X.A.; Teetsov, J.A.; Shahedipour-Sandvik, F.; Arthur, S.D. Microstructural origin of leakage current in GaN/InGa light-emitting diodes. J. Cryst. Growth 2004, 264, 172-177. [CrossRef]

7. Wang, R.P.; Muto, H.; Yamada, Y.; Kusumori, T. Effect of Zno buffer layer on the quality of GaN films deposited by pulsed laser ablation. Thin Solid Films 2000, 411, 69-75. [CrossRef]

8. Gu, H.; Ren, G.; Zhou, T.; Tian, F.; Xu, Y.; Zhang, Y.; Wang, M.; Zhang, Z.; Cai, D.; Wang, J.; Xu, K. Study of optical properties of bulk GaN crystals grown by HVPE. J. Alloys Compd. 2016, 674, 218-222. [CrossRef]

9. Wang, W.K.; Wuu, D.S.; Lin, S.H.; Huang, S.Y.; Wen, K.S.; Horng, R.H. Growth and characterization of InGaN-based light-emitting diodes on patterned sapphire substrates. J. Phys. Chem. Solids 2008, 69, 714-718. [CrossRef] 
10. Sienz, S.; Gerlach, J.W.; Hoche, T.; Sidorenko, A.; Mayerhofer, T.G.; Benndorf, G.; Rauschenbach, B. Comparison of ion-beam-assisted molecular beam epitaxy with conventional molecular beam epitaxy of thin hexagonal gallium nitride films. J. Cryst. Growth 2004, 264, 184-191. [CrossRef]

11. Poppitz, D.; Lotnyk, A.; Gerlach, J.W.; Lenzner, J.; Grandmann, M.; Rauschenbach, B. An aberration-corrected STEM study of structural defects in epitaxial GaN thin films grown by ion beam assisted MBE. Micron 2015, 73, 1-8. [CrossRef] [PubMed]

12. Shen, K.C.; Wang, T.Y.; Wuu, D.S.; Horng, R.H. High thermal stability of high indium content InGaN films grown by pulsed laser deposition. Opt. Express 2012, 20, 21173-21180. [CrossRef] [PubMed]

13. Kawwama, M.; Lebbou, K. The influence of deposition parameters on the structural quality of PLD-grown GaN/sapphire thin films. Appl. Surf. Sci. 2014, 292, 906-914. [CrossRef]

14. Wang, L.D.; Kwok, H.S. Cubic aluminum nitride and gallium nitride thin films prepared by pulsed laser deposition. Appl. Surf. Sci. 2000, 154-155, 439-443. [CrossRef]

15. Yoshida, A.; Ouyang, K.; Chang, B.S.; Wakahara, A. Epitaxial growth nitride semiconductor films by laser ablation. Thin Solid Films 1999, 343-344, 127-129. [CrossRef]

16. Sangulno, P.; Schwarz, R.; Wilhelm, M.; Kunst, M.; Teodoro, O. Morphology and composition of GaN films grown by cyclic-pulsed laser deposition. Vacuum 2007, 81, 1524-1528. [CrossRef]

17. Guo, H.; Chen, W.; Shen, W.; Zhang, Z.; Jia, J. Microstructures and properties of titanium nitride films prepared by pulsed laser deposition at different substrate temperatures. Appl. Surf. Sci. 2015, 357, 473-478. [CrossRef]

18. Cheng, Y.W.; Wu, H.Y.; Lin, Y.Z.; Lee, C.C.; Lin, C.F. Post-annealing effects on pulsed laser deposition-grown GaN thin films. Thin Solid Films 2015, 577, 17-25. [CrossRef]

19. Zhang, D.; Guan, L.; Li, Z.; Pan, G.; Tan, X.; Li, L. Simulation of island aggregation influenced by substrate temperature, incidence kinetic energy and intensity in pulsed laser deposition. Appl. Surf. Sci. 2006, 253, 874-880. [CrossRef]

20. Yang, H.; Wang, W.; Liu, Z.; Li, G. Homogeneous epitaxial growth of AlN single-crystalline films on 2 inch-diameter Si (111) substrates by pulsed laser deposition. Cryst. Eng. Comm. 2013, 15, 7171-7176. [CrossRef]

21. Wang, W.; Yang, W.; Liu, Z.; Lin, Y.; Zhou, S.; Qian, H.; Gao, F.; Yang, H.; Li, G. Epitaxial growth of homogeneous single-crystalline AlN films on single-crystalline $\mathrm{Cu}$ (111) substrates. Appl. Surf. Sci. 2014, 294, 1-8. [CrossRef]

22. Yoo, J.; Shojiki, K.; Tanikawa, T.; Kuboya, S.; Hanada, T.; Katayama, R.; Matsuoka, T. Polarity control of GaN grown on pulsed-laser-deposited AlN/GaN template by metalorganic vapor phase epitaxy. J. Appl. Phys. 2016, 55. [CrossRef]

23. Wang, W.; Yang, W.; Li, G. Quality-enhanced GaN epitaxial films grown on ( $\mathrm{La}, \mathrm{Sr})(\mathrm{Al}, \mathrm{Ta}) \mathrm{O}_{3}$ substrates by pulsed laser deposition. Mater. Lett. 2016, 168, 52-55. [CrossRef]

24. Kumar, M.S.; Kushvaha, S.S.; Maurya, K.K. Low Temperature growth of GaN epitaxial layers on sapphire (0001) by pulsed laser deposition using liquid gallium target. Sci. Adv. Mater. 2014, 6, 1215-1220. [CrossRef]

25. Sedhain, A.; Li, J.; Lin, J.Y.; Jiang, H.X. Nature of deep center emissions in GaN. Appl. Phys. Lett. 2010, 96, 151902. [CrossRef]

26. Xi, X.Z.; Man, B.Y.; Chen, C.S.; Liu, M.; Wei, J.; Yang, S.Y. Effects of annealing temperature on amorphous GaN films formed on Si(111) by pulsed laser deposition. Semicond. Sci. Tech. 2009, 24. [CrossRef]

27. Li, G.; Wang, W.; Yang, W.; Wang, H. Epitaxial growth of group III-nitride films by pulsed laser deposition and their use in the development of LED devices. Surf. Sci. Rep. 2015, 70, 380-423. [CrossRef]

28. Sudhir, G.S.; Fujii, H.; Wong, W.S.; Kisielowski, C.; Newman, N.; Dieker, C.; Liliental-Weber, Z.; Rubin, M.D.; Weber, E.R. Pulsed laser deposition of aluminum nitride and gallium nitride thin films. Appl. Surf. Sci. 1998, 471, 127-129. [CrossRef]

29. Wang, W.K.; Jiang, M.C. Growth behavior of hexagonal GaN on $\mathrm{Si}(100)$ and $\mathrm{Si}(111)$ substrates prepared by pulsed laser deposition. Jpn. J. Appl. Phys. 2016, 55. [CrossRef]

30. Tong, X.L.; Zheng, Q.G.; Hu, S.L.; Qin, Y.X.; Ding, Z.H. Structural characterization and optoelectronic properties of $\mathrm{GaN}$ thin films on $\mathrm{Si}(111)$ substrates using pulsed laser deposition assisted by gas discharge. Appl. Phys. A 2004, 79, 1959-1963. [CrossRef] 
31. Tang, H.; Kim, W.; Botchkarev, A.; Popovici, G.; Hamdani, F.; Morkoc, H. Analysis of carrier mobility and concentration in Si-doped GaN grown by reactive molecular beam epitaxy. Solid State Electrochem. 1998, 42, 839-847. [CrossRef]

32. Lee, F.W.; Ke, W.C.; Chen, C.H.; Laio, B.W.; Chen, W.K. Influence of different aspect ratios on the structural and electrical properties of GaN thin films grown on nanoscale-patterned sapphire substrates. Appl. Surf. Sci. 2016, 375, 223-229. [CrossRef]

33. Park, B.; Saravana Kumar, R.; Moon, M.; Kim, M.; Kang, T.; Yang, W.; Kim, S. Comparison of stress states in GaN films grown on different substrates: Langasite, sapphire and silicon. J. Cryst. Growth 2015, 425, 149-153. [CrossRef]

34. Davydov, V.Y.; Averkiev, N.S.; Goncharuk, I.N.; Nelson, D.K.; Nikitina, I.P.; Polkovnikov, A.S.; Smirnov, A.N.; Jacobson, M.A.; Semchinova, O.K. Raman and photoluminescence studies of biaxial strain in GaN epitaxial layers grown on 6H-SiC. J. Appl. Phys. 1997, 82, 5097-5102. [CrossRef]

35. Benyoucef, M.; Kuball, M.; Beaumont, B.; Gibart, P. Raman mapping, photoluminescence investigations, and finite element analysis of epitaxial lateral overgrown GaN on silicon substrates. Appl. Phys. Lett. 2002, 80, 2275-2277. [CrossRef]

36. Kozawa, T.; Kachi, T.; Kano, H.; Nagase, H.; Koide, N.; Manabe, K. Thermal stress in GaN epitaxial layers grown on sapphire substrates. J. Appl. Phys. 1995, 77, 4389-4392. [CrossRef]

37. Wang, H.; Wang, W.; Yang, W.; Zhn, Y.; Lin, Z.; Li, G. Effect of residual stress on the microstructure of GaN epitaxial films grown by pulsed laser deposition. Appl. Surf. Sci. 2016, 369, 414-421. [CrossRef]

38. Widmann, F.; Feuillet, G.; Daudin, B.; Rouviere, J.L. Low temperature sapphire nitridation: A clue to optimize GaN layers grown by molecular beam epitaxy. J. Appl. Phys. 1999, 85, 1550-1555. [CrossRef]

39. Dadgar, A.; Poschenrieder, M.; Blasing, J.; Contreras, O.; Bertram, F.; Riemann, T.; Reiher, A.; Kunze, M.; Daumiller, I.; Krtschil, A.; et al. MOVPE growth of GaN on Si(111) substrates. J. Cryst. Growth 2003, 248, 556-562. [CrossRef]

40. Ishikawa, H.; Yamamoto, K.; Egawa, T.; Soga, T.; Jimbo, T.; Umeno, M. Thermal stability of GaN on (111) Si substrate. J. Cryst. Growth 1998, 189, 178-182. [CrossRef]

(C) 2017 by the authors; licensee MDPI, Basel, Switzerland. This article is an open access article distributed under the terms and conditions of the Creative Commons Attribution (CC-BY) license (http:/ / creativecommons.org/licenses/by/4.0/). 